\title{
TIDAL CURRENT MEASUREMENT WITH TERRASAR-X ALONG-TRACK INTERFEROMETRY
}

\author{
Steffen Suchandt ${ }^{1}$, Hartmut Runge ${ }^{1}$, Roland Romeiser ${ }^{2}$, Núria Tous-Ramon ${ }^{1}$, Ulrich Steinbrecher ${ }^{1}$ \\ ${ }^{1}$ German Aerospace Center (DLR), D-82234 Wessling, Germany \\ ${ }^{2}$ University of Miami, Rosenstiel School of Marine and Atmospheric Science
}

Corresponding author: Steffen.Suchandt@dlr.de Phone: +49 81532830 11, Fax: +49 8153281420

\section{INTRODUCTION}

Measurement of ocean surface currents with SAR Along-Track Interferometry (ATI) was shown first in [1]. With X-Band data of the Shuttle Radar Topography Mission (SRTM) tidal currents in the Dutch Waddenzee were mapped from space [2]. The application of mapping tidal currents based on SRTM ATI data for the exploration of promising sites for hydro-power installations has been addressed in [3]. Results from river surface current measurements obtained with the TerraSAR-X satellite have been published in [4].

In this paper we present further achievements of surface current measurements obtained by TerraSAR-X AlongTrack Interferometry. We apply a modified version of the TS-X Traffic Processor TTP [5][6] for data processing. The TTP has been developed for the automatic detection and measurement of traffic flows. With slight modifications it can also be used to estimate the velocity of distributed radar targets like water surfaces. TerraSAR-X can realize ATI in two ways - either by switching the attenuation of different antenna parts on a pulse-by-pulse basis (Aperture Switching, AS mode) or by splitting the antenna in along-track and using two receiver chains (Dual-Receive Antenna, DRA mode). Due to the very low velocities of tidal currents, the sensor needs to be very sensitive, i.e. the effective along-track baseline $B_{\text {eff }}$ must be as large as possible. For first evaluations we have used the TS-X AS mode in a special configuration, where $B_{\text {eff }}$ is $1 \mathrm{~m}$.

\section{RESULTS}

Fig. 1 shows a first result, where TerraSAR-X imaged the Orkney islands on Nov. 12, 2009 at UTC 06:41:14. Shown are the SAR amplitude, the interferometric coherence and an estimation of the surface current ground velocity in the sensor look direction rg (overlaid by the SAR image for land). As the surface current induced ATI phase $\phi_{A T I}$ is hidden within phase noise, strong coherent averaging is applied in the image range and azimuth dimension. Then, ATI phase is converted to ground-range velocities $v_{g}$ after 


$$
v_{g}=\frac{\phi_{A T I} \cdot \lambda \cdot v_{s}}{4 \pi \cdot B_{e f f} \cdot \sin (\vartheta)}
$$

$\lambda$ being the radar wavelength, $v_{s}$ the sensor velocity and $\vartheta$ the local incidence angle. Please note that corrections for wind and wave speeds have not yet been applied, but refined results will be presented at the conference.

Positive / negative velocities indicate motions away / towards the Radar. In the mid and lower part of the velocity image, one can recognize areas that are very close to each other but have velocities of opposite sign. These counter currents are also unveiled in results from in situ-measurements published in [7]. A second example, where ocean surface velocity over the Orkney region has been retrieved from TS-X ATI is shown in Figure 2.
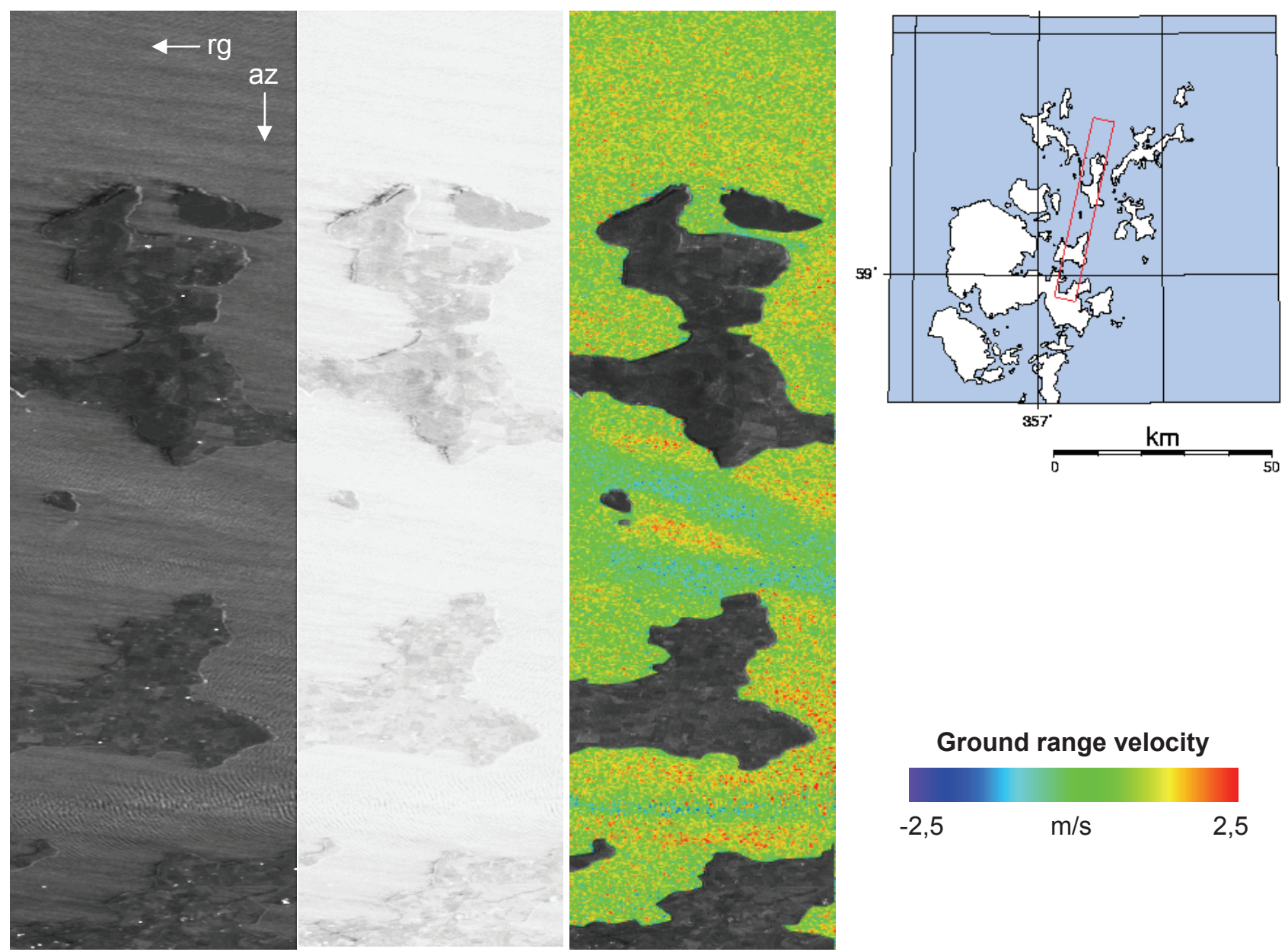

Figure 1: Part of TerraSAR-X AS mode data take DT09020, 12.11.2009 over the Orkney Islands. Shown are the

SAR image, the interferometric coherence, the surface current ground-range velocity estimated from ATI phase (overlaid by the SAR image for land) and the geographic location of the acquisition (left to right). 


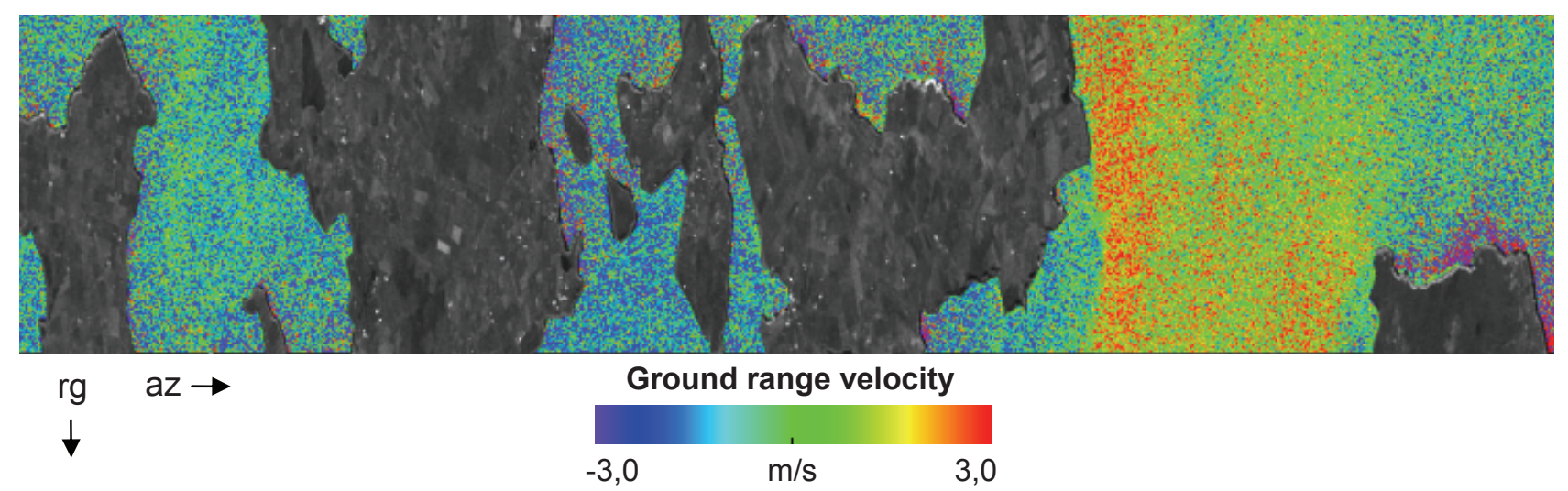

Figure 2: TerraSAR-X AS mode data take DT09674, 23.11. 2009, UTC 06:41:12 over the Orkney Islands. The surface current ground-range velocity obtained from the ATI phase is shown in radar coordinates.

\section{CONCLUSION AND OUTLOOK}

First results have been presented that show the capability of TerraSAR-X ATI to map tidal currents. The sensitivity of the sensor can even be improved by up to $40 \%$ using the DRA mode compared to the used AS configuration in the examples. The DRA mode allows for ATI baselines of up to $1.4 \mathrm{~m}$. Until the conference we plan to evaluate further AS and DRA mode data takes, apply corrections for wind and wave contributions and to compare estimates from the TerraSAR-X data with ground truth measurements. Furthermore, it will be interesting to see how the ATI results compare to those from the Doppler method [8]. For the future the upcoming TanDEM$\mathrm{X}$ mission will offer a space based along-track interferometer with even higher sensitivity [9].

\section{REFERENCES}

[1] R. M. Goldstein, H.A. Zebker, "Interferometric radar measurement of ocean surface currents," Nature 328, 707-709, 1987.

[2] R. Romeiser, H. Breit, M. Eineder, H. Runge, P. Flamant, K. de Jong, J. Vogelzang, "Current Measurements by SAR Along-Track Interferometry from a Space Shuttle,“ IEEE Trans. Geoscience Remote Sensing, Vol. 43, No. 10, pp. 2315-2324, 2005.

[3] H. Runge, S. Suchandt, H. Breit, M. Eineder, J. Schulz-Stellenfleth, J. Bard, R. Romeiser, "Mapping Of Tidal Currents With SAR Along Track Interferometry”, Proc. IGARSS'04, 20.-24. September 2004, Anchorage, Alaska, USA.

[4] R. Romeiser, S. Suchandt, H. Runge, U. Steinbrecher, "High-Resolution Current Measurements from Space with TerraSAR-X Along-Track InSAR,” Proc. IEEE Oceans 2009, 11.-14. May, 2009, Bremen, Germany. 
[5] S. Suchandt, H. Runge, A. Kotenkov, H. Breit, U. Steinbrecher, "Extraction of Traffic Flows and Surface Currents using TerraSAR-X Along-Track Interferometry Data," Proc. IGARSS'09, 12.-17. July 2009, Cape Town, South Africa.

[6] S. Suchandt, H. Runge, H. Breit, U. Steinbrecher, A. Kotenkov, U. Balss, "Automatic Extraction of Traffic Flows using TerraSAR-X Along-Track Interferometry,” IEEE Trans. Geoscience Remote Sensing, vol. 48, 2010 (in press).

[7] L. Lawrence, H. Kofoed-Hansen, C. Chevalier, "High-resolution metocean modeling at EMEC's (UK) marine energy test sites", Proc. $8^{\text {th }}$ European Wave and Tidal Energy Conference, 7.-10. September, Uppsala, Sweden, 2009.

[8] B. Chapron, F. Collard, F. Ardhuin, "Direct measurements of ocean surface velocity from space: Interpretation and validation", J. Geophys. Res., 110, C07008, 2005.

[9] G. Krieger, A. Moreira, H. Fiedler, I. Hajnsek, M. Werner, M. Younis, M. Zink, "TanDEM-X: A Satellite Formation for High-Resolution SAR Interferometry," IEEE Trans. Geoscience Remote Sensing, vol. 45, No. 11, November 2007, pp.3317-3341. 